\title{
Study of RF-MEMS Capacitive Shunt Switch for Microwave Backhaul Applications
}

\author{
Dharti Raj Shah ${ }^{1}$, Ritu Sharma ${ }^{2}$, Hemant Kumar Varshney ${ }^{3}$, Shagufta Parveen \\ Asif Akhtar ${ }^{4}$ \\ ${ }^{I}$ (Asst. Prof., Dept. of ECE, KNGD Modi Engineering College, Modinagar, India) \\ ${ }^{2}$ (Asst. Prof., Dept. of ECE, Subharti Institute of Technology \& Engineering, Meerut, India) \\ ${ }^{3}$ (Asst. Prof., Dept. of ECE, Dr. B R A College of Agriculture Engg. \& Technology, Etawah, India) \\ ${ }^{4}$ (Asst. Prof., Dept. of ECE, Vidya College of Engineering, Meerut, India)
}

\begin{abstract}
In this research paper, we have proposed a new type of capacitive shunt RF-MEMS switch. MicroElectro-Mechanical System (MEMS) is a combination of mechanical and electromagnetics properties at micro level unit. This MEMS switch can be used for switching purpose at $R F$ and microwave frequencies, called RFMEMS switch. The RF-MEMS switch has a potential characteristics and superior performances at radio frequency. The MEMS switch has excellent advantages such as zero power consumption, high power handling capacity, high performance, and low inter-modulation distortion. In this proposed design, a new type of capacitive shunt switch is designed and analyzed for RF applications. The switch is designed both in UP and DOWN-states. The proposed switch design consists of substrate, co-planar waveguide $(C P W)$, dielectric material and suspended metallic bridge. The proposed MEMS switch has dimension of $508 \mu \mathrm{m} \times 620 \mu \mathrm{m}$ with a height of $500 \mu \mathrm{m}$ and implemented on GaAs as a substrate material with relative permittivity of 12.9. The geometry and results of the proposed switch is designed using Ansoft HFSS electromagnetic simulator based on finite element method (FEM). The electrostatic and electromagnetic result showed better performances such as return loss, insertion loss and isolation. The switch has also excellent isolation property of $-48 \mathrm{~dB}$ at $26 \mathrm{GHz}$.
\end{abstract}

Keywords: Capacitive shunt, RF-MEMS, Substrate, CPW, Dielectric, FEM, Return loss, Insertion loss, Isolation

\section{Introduction}

MEMS refer to the Micro-Electro-Mechanical System and arrangement of electromagnetics and mechanical systems. The MEMS switches have the capability to combine advantages of electro-mechanical and semiconductor technologies based switches. In particular, MEMS switches offer the high RF performance and low DC power consumption of electro-mechanical switches but with the size and cost features of semiconductor switches. MEMS switch can be employed in radio frequency RF circuits, and their performances could be made better than those of other standard switches such as FET, and PIN diodes [1-2]. In recent years, a large number of research have been done on MEMS switch to use as switching application at radio frequency due to the larger number of advantages such as low speed, zero power consumption, low insertion loss, high isolation and very low intermodulation over the convention switching devices [3-5]. In 1970's, MEMS has been used for pressure and temperature sensors, accelerometers, gas chromatographs and sensor devices and MEMS switches for low frequency applications have also been established [6-9]. Over the available conventional solid state switching devices like PIN diode and FET, the RF-MEMS switch has numerous potential advantages for switching function and performs better performance including high bandwidth and good linearity [10]. On the other hand, the RF-MEMS switch has also some limitations during designing and operation such as low power handling, switching speed, low switching lifetime, high actuation voltage and electrostatic discharge [11-14]. To overcome the challenges faced in RF-MEMS switch, many of researchers have designed and analyzed different types of switches in which different techniques and switching parameters are considered like actuation voltage of switch and switching speed of switch. Piezoelectric actuation and spring constant parameters are responsible for actuation voltage whereas switching speed performance is improved by using different types of shape in bridges like meander, creating rectangular slot in bridge [15-20].

In this paper, a capacitive shunt type MEMS switch is designed and analyzed for RF applications. The objective of designing this switch is to improve the electromagnetics and mechanical characteristics such as return loss, isolation and actuation voltage. In this design, the bridge length is reduced to half as compare to old design to improve the spring constant and actuation voltage properties and the bridge has also five identical cylindrical slots above the actuation pad to minimize the stickiness between bridge and electrode during actuation time. 


\section{RF-MEMS Switch Design Geomerty}

According to applications, the designing structures of RF-MEMS switches are different like Ohmic, capacitive, series, shunt etc. In the proposed design, the switch is capacitive and shunts type in nature. The switch consists of several layers such as substrate, silicon dioxide layer, CPW, silicon nitride dielectric layer and a metallic bridge. The material used for bridge and $\mathrm{CPW}$ is gold.

Fig.1. shows the HFSS design structure of the proposed MEMS switch.

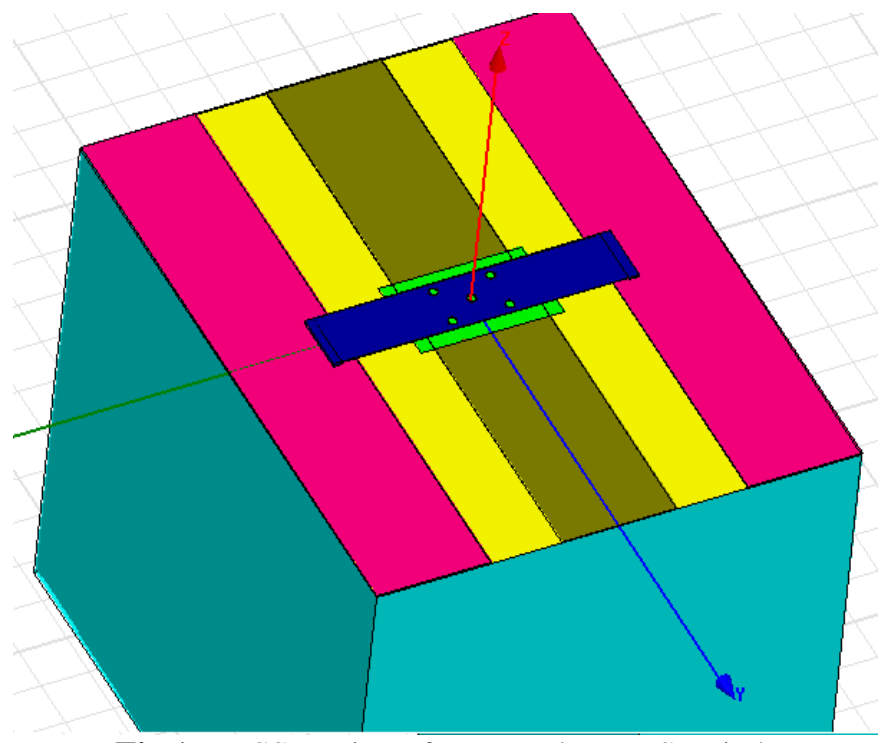

Fig.1. HFSS Design of proposed MEMS switch

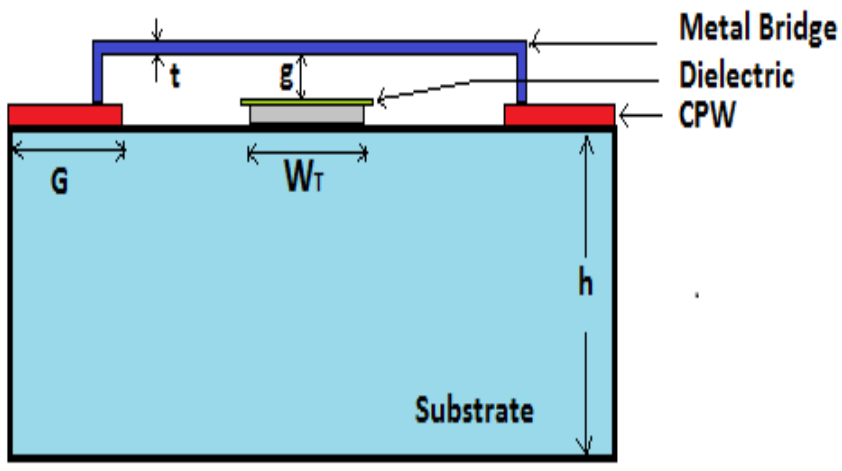

Fig.2. General View of proposed MEMS switch

In the above fig.2, a general view of the proposed MEMS switch is presented. The MEMS switch with different structures of substrate, silicon dioxide, dielectric material, and suspended bridge. The substrate is GaAs material having dimension of $508 \mu \mathrm{m} \times 620 \mu \mathrm{m} \times 500 \mu \mathrm{m}$ with permittivity of 12.9 . On the top surface of substrate, a thin layer of silicon dioxide layer is deposited of thickness $0.5 \mu \mathrm{m}$. In the proposed design, the MEMS switch consists of three identical CPW of each dimension of $120 \mu \mathrm{m} \times 620 \mu \mathrm{m} \times 1 \mu \mathrm{m}$. The middle CPW behaves as a transmission line where the RF signal is given as an input and the other two CPWs acts as ground. In capacitive shunt switch, a thin layer of dielectric material is used to separate two conduction electrodes bridge and CPW during actuation and it prevents the direct metal to metal contact. The material used for dielectric is silicon nitride $\left(\mathrm{Si}_{3} \mathrm{~N}_{4}\right)$ and its dimension is $150 \mu \mathrm{m} \times 90 \mu \mathrm{m} \times 0.15 \mu \mathrm{m}$ is deposited on the top surface of middle CPW and the dielectric thickness ' $t_{d}$ ' with a dielectric constant $\varepsilon_{\mathrm{r}}$. As shown in fig.2 the capacitive shunt switch consists of a movable metal bridge of gold material, suspended at a height ' $\mathrm{g}$ ' above the dielectric layer on the transmission line mechanically anchored and electrically connected to ground of the coplanar waveguide $(\mathrm{CPW})$. The bridge is $\mathrm{L}_{\mathrm{B}} \mu \mathrm{m}$ long, $\mathrm{W}_{\mathrm{B}} \mu \mathrm{m}$ wide and $\mathrm{t} \mu \mathrm{m}$ thick. The dimension of rectangular bridge is $320 \mu \mathrm{m} \times 60 \mu \mathrm{m}$ and thickness is $1 \mu \mathrm{m}$. 


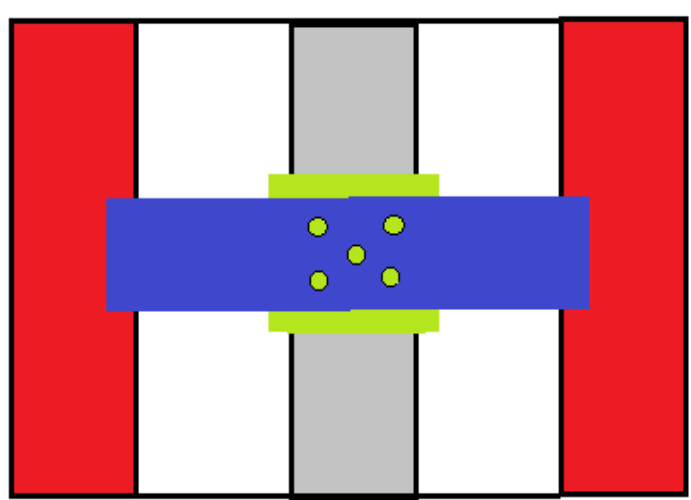

Fig.3. Top view of proposed MEMS switch

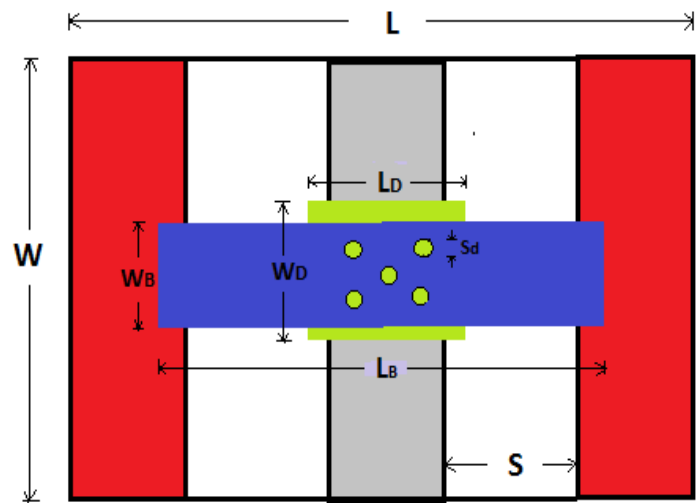

Fig.4. Design parameters of proposed MEMS switch

The RF-MEMS switch is mechanically designed in such a way that the metallic gold bridge is suspended $2 \mu \mathrm{m}$ above the dielectric electrode. In the design technique, the length of bridge is reducing to minimize the actuation voltage and spring constant. Similarly the proposed switch has also five identical cylindrical slots above the transmission line due to this the stickiness between electrode and metallic bridge is minimized during actuation period. The dimension of each cylindrical slot is of radius $4.5 \mu \mathrm{m}$ with height of 1 $\mu \mathrm{m}$.

Table1. MEMS Switch Design Parameters and Dimensions

\begin{tabular}{|c|c|c|c|}
\hline $\begin{array}{c}\text { Switch } \\
\text { Parameters }\end{array}$ & $\begin{array}{c}\text { Dimension } \\
(\mu \mathrm{m})\end{array}$ & $\begin{array}{c}\text { Switch } \\
\text { Parameters }\end{array}$ & $\begin{array}{c}\text { Dimension } \\
(\mu \mathbf{m})\end{array}$ \\
\hline $\mathbf{L}$ & $\mathbf{5 0 8}$ & $\mathbf{W}_{\mathbf{D}}$ & $\mathbf{9 0}$ \\
\hline $\mathbf{W}$ & $\mathbf{6 2 0}$ & $\mathbf{S}$ & $\mathbf{7 4}$ \\
\hline $\mathbf{G}$ & $\mathbf{1 2 0}$ & $\mathbf{G}$ & $\mathbf{2}$ \\
\hline $\mathbf{W}_{\mathbf{T}}$ & $\mathbf{1 2 0}$ & $\mathbf{T}$ & $\mathbf{1}$ \\
\hline $\mathbf{L}_{\mathbf{B}}$ & $\mathbf{3 2 0}$ & $\mathbf{S}_{\mathbf{d}}$ & $\mathbf{9}$ \\
\hline $\mathbf{W}_{\mathbf{B}}$ & $\mathbf{6 0}$ & $\mathbf{H}$ & $\mathbf{5 0 0}$ \\
\hline $\mathbf{L}_{\mathbf{D}}$ & $\mathbf{1 5 0}$ & $\mathbf{t}_{\mathbf{d}}$ & $\mathbf{0 . 1 5}$ \\
\hline
\end{tabular}

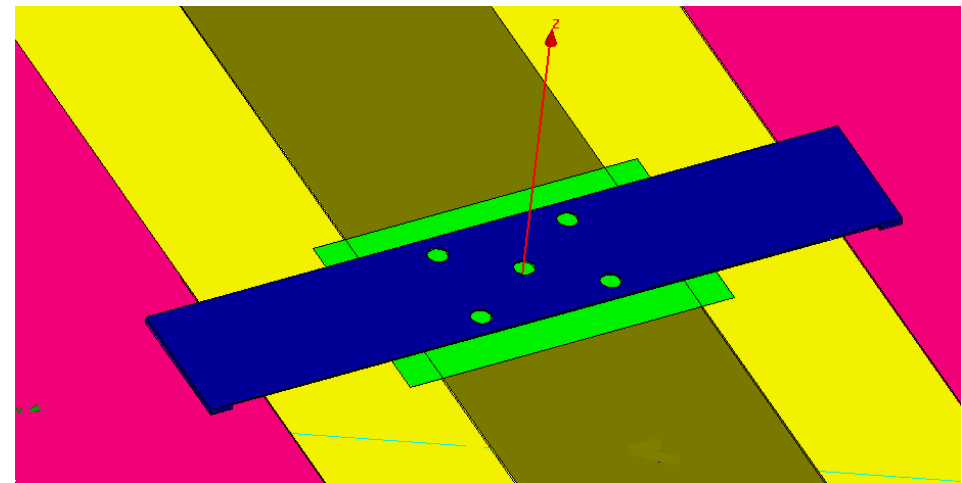

(a) MEMS switch in UP-state

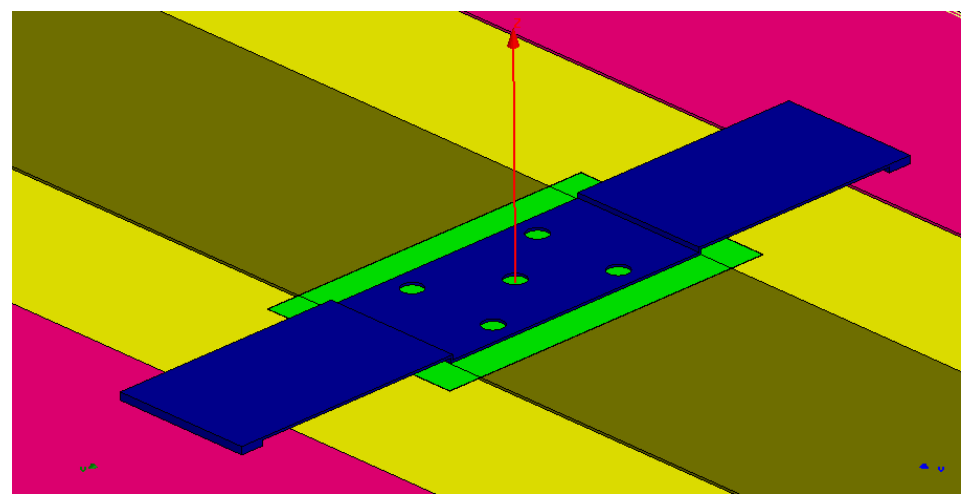

(b) MEMS switch in DOWN-state

Fig.5. HFSS Design of proposed RF-MEMS capacitive shunt switch (a) UP-state (b) DOWN-state 


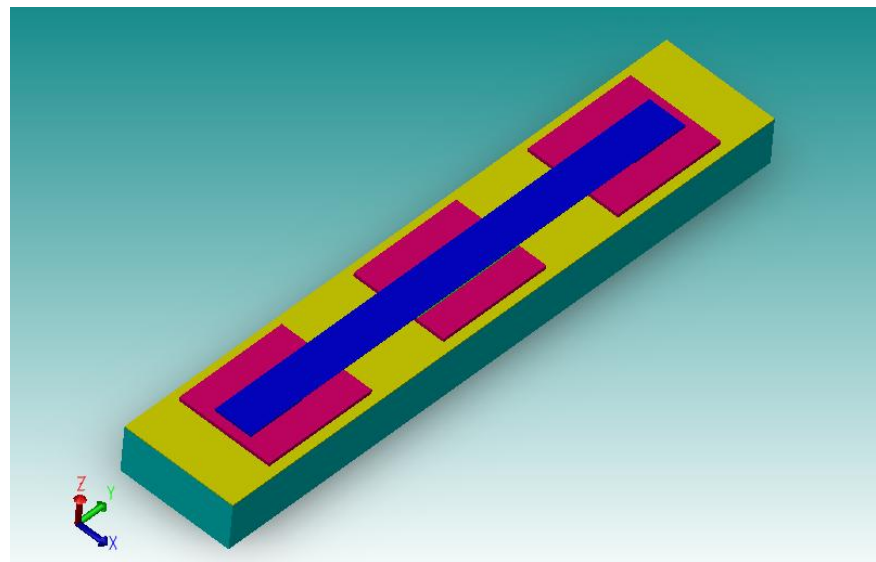

(a) MEMS switch in UP-state

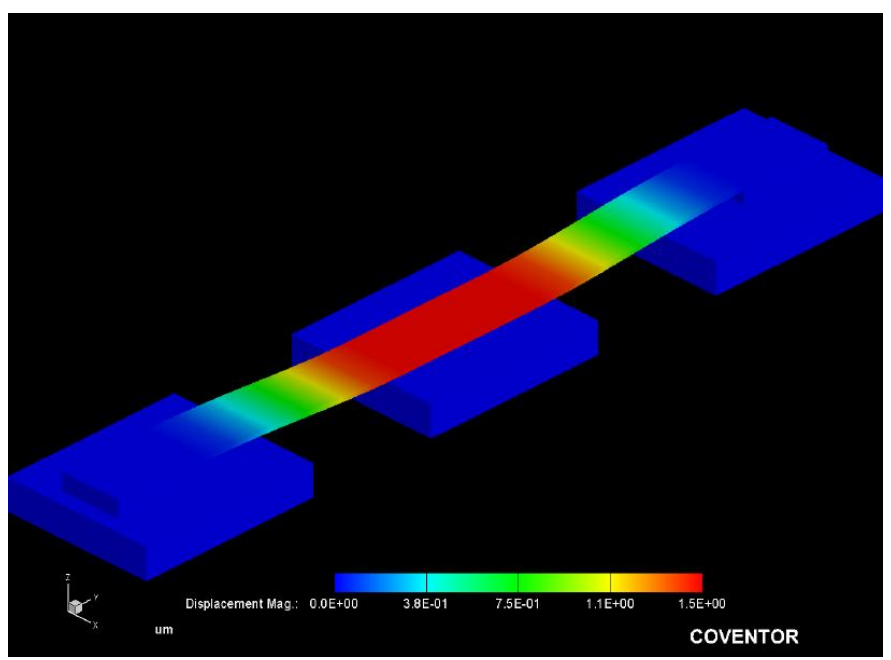

(b) MEMS switch in DOWN-state

Fig.6. COVENTORWARE Design of proposed RF-MEMS capacitive shunt switch without cylindrical slot (a) UP-state (b) DOWN-state

\section{Working Principle Of RF-MEMS Switch}

The MEMS switch can be operate in two states: UP and DOWN states. In UP-state the switch is "on" and RF signal applied the center CPW is transmitted to the output port. In DOWN state the switch is normally "off" condition hence the applied RF signal to the transmission line is given to the ground CPW by shorting the bridge with center transmission pad. When an actuation voltage is applied between the actuation electrode and the suspended beam, the suspended beam will move downward and collapse on the bottom electrode.

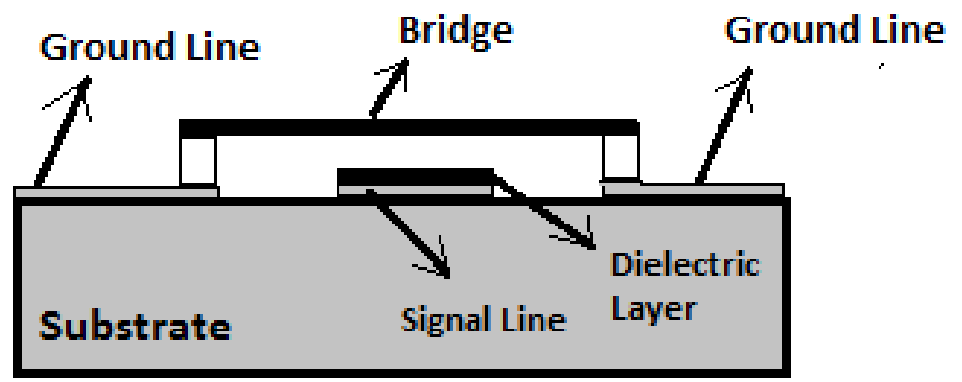

Fig.7. RF-MEMS shunt switch in UP-state 


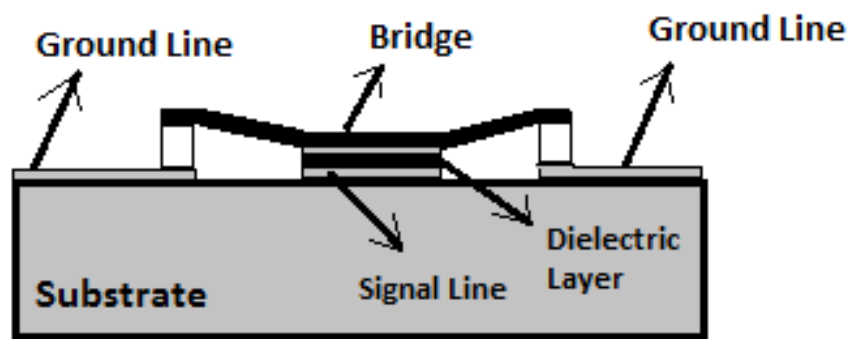

Fig.8. RF-MEMS shunt switch in DOWN-state

During the actuation, the force due to which the bridge moves towards the electrode is electrostatic force and this is due to charge accumulated between the bridge and electrode. The electrostatic force is given by

$$
F_{e}=\frac{\varepsilon_{0} A V^{2}}{2\left(g+\frac{t_{d}}{\varepsilon_{r}}\right)}
$$

Where $\mathrm{A}$ is the area of actuation electrode, $\mathrm{V}$ is applied actuation voltage, $\mathrm{g}$ is the air gap between bridge and dielectric material, $t_{d}$ is dielectric thickness and is relative permittivity. From above eq, it observed that force depends upon area, actuation voltage and air gap between bridge and electrode.

\section{Electromagnetic Modeling of RF-MEMS Switch}

The modeling analysis of RF-MEMS switch can be performed in two domain i.e. electrical and mechanical domain. In electrical modeling, the switch is modeled with respect to their electrical or electromagnetic parameters like resonance frequency, electrical equivalent impedance, return loss, insertion loss and isolation.

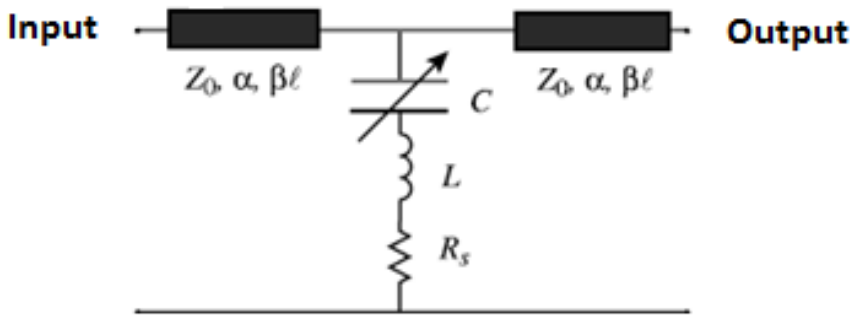

Fig.9. Electrical equivalent circuit of RF-MEMS shunt switch

The switch shunt impedance is given by

$$
Z_{s}=R_{s}+j \omega L+\frac{1}{j \omega C}
$$

Where $\mathrm{R}$ is the resistance of the switch and it depends upon the resistance of bridge and transmission line.

The impedance of the RF switch is given by

$$
Z_{s}=\left\{\begin{array}{c}
\frac{1}{j \omega C}, f<<f_{0} \\
R_{s}, f=f_{0} \\
j \omega L, f>>f_{0}
\end{array}\right.
$$

Where $\mathrm{f}_{0}$ is the resonance frequency of the LC switch and it is given by 


$$
f_{0}=\frac{1}{2 \pi} \frac{1}{\sqrt{L C}}
$$

The return loss and insertion loss of RF-MEMS switch is given by

$$
\begin{gathered}
S_{11}=\frac{-j \omega C_{u} Z_{0}}{2+j \omega C_{u} Z_{0}} \\
S_{21}=\frac{1}{1+j \omega C_{d} Z_{0} / 2}
\end{gathered}
$$

Where $\mathrm{C}_{\mathrm{u}}$ and $\mathrm{C}_{\mathrm{d}}$ are the up-state and down-state capacitances and are given by

$$
\begin{gathered}
C_{u}=\frac{\varepsilon_{0} A}{g_{0}+\frac{t_{d}}{\varepsilon_{r}}} \\
C_{d}=\frac{\varepsilon_{0} \varepsilon_{r} A}{t_{d}}
\end{gathered}
$$

The Up-state/Down-state capacitance ratio is

$$
\frac{C_{d}}{C_{u}}=\frac{\frac{\varepsilon_{0} \varepsilon_{r} A}{t_{d}}}{\frac{\varepsilon_{0} A}{g+\frac{t_{d}}{\varepsilon_{r}}}+C_{f}}
$$

In mechanical modelling, the switch is designed in such a way that the mechanical parameters like switching speed, spring constant and actuation voltage can be improved. The actuation voltage of switch is given by

$$
V_{p}=\sqrt{\frac{8 k}{27 A \varepsilon_{0}} g_{0}{ }^{3}}
$$

\section{Simulation Result And Analysis}

The simulated results of the proposed RF-MEMS switch are illustrated in following fig. The simulation of switch is done with the help of HFSS simulation tool [21].

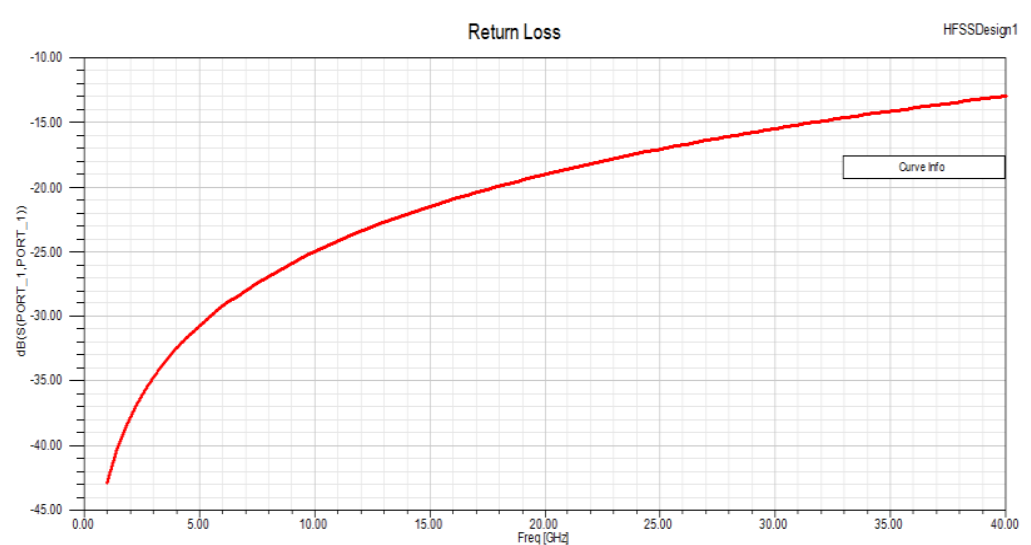

(a) Return loss 


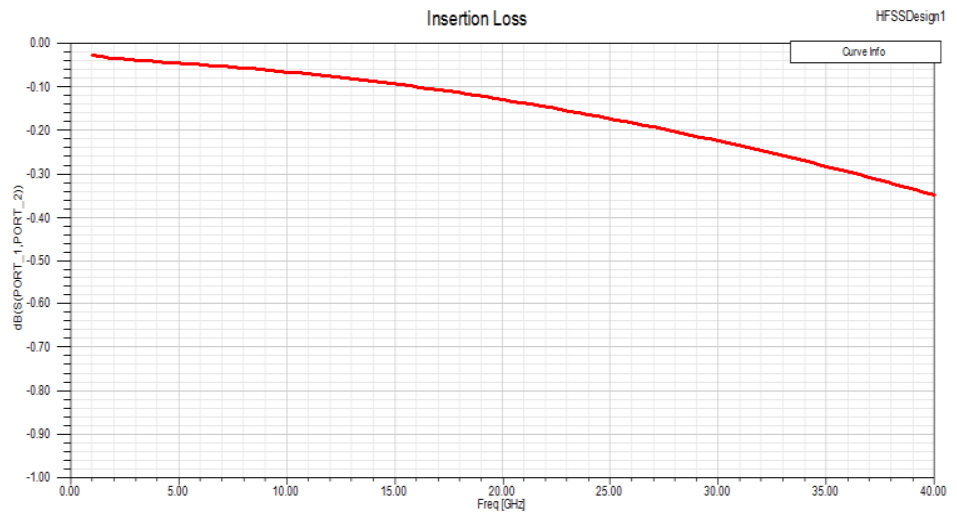

(b) Insertion loss

Fig.10. Simulated results of proposed RF-MEMS shunt switch in UP-state

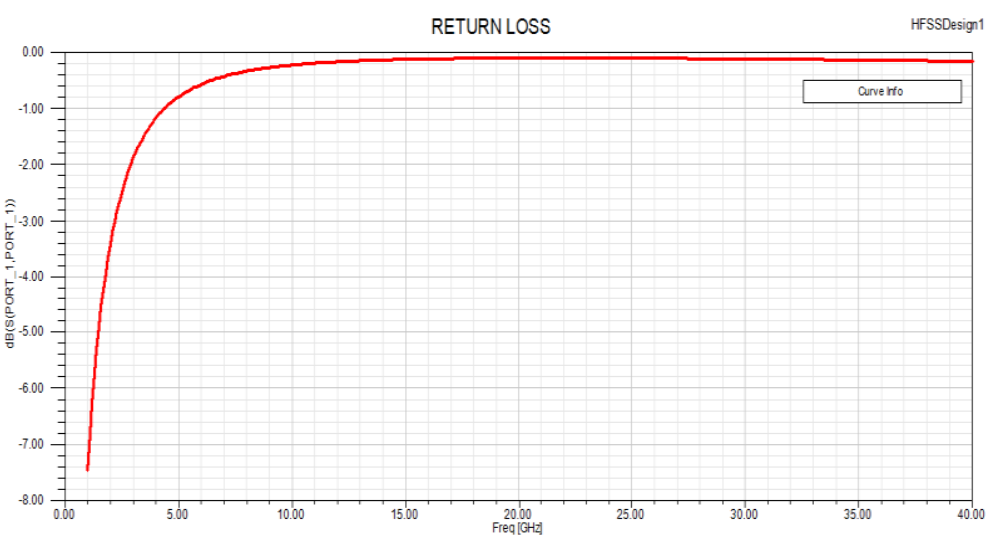

(a) Return loss

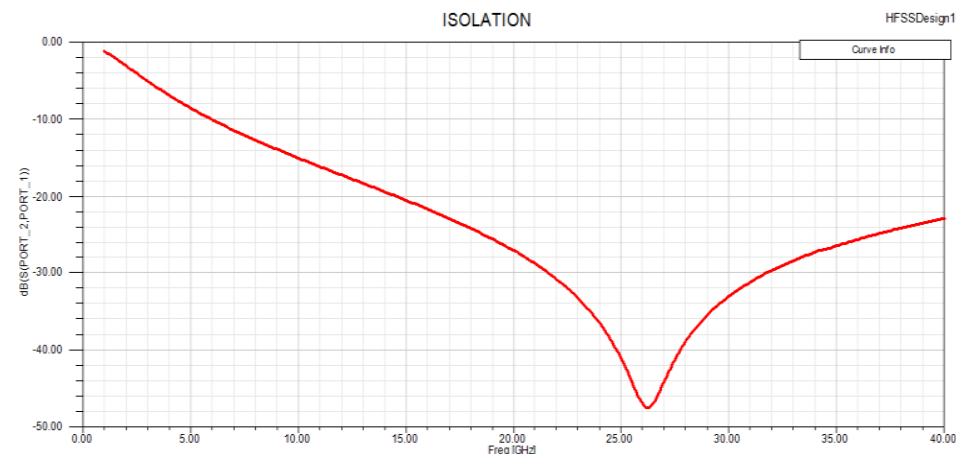

(b) Isolation

Fig.11. Simulated results of proposed RF-MEMS shunt switch in DOWN-state

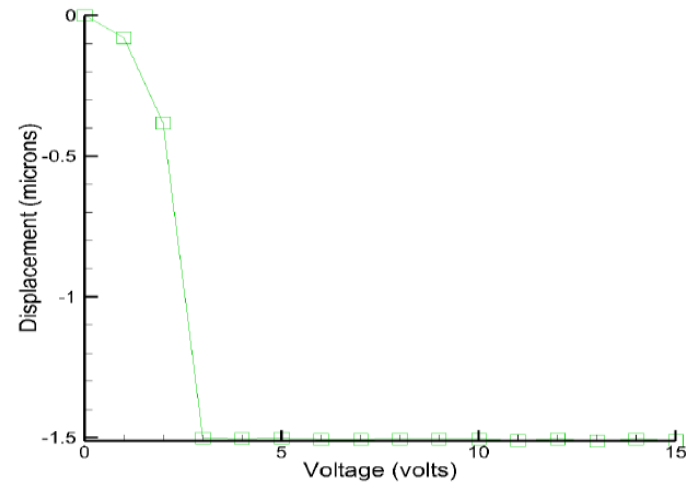

Fig.12. Simulated actuation voltage vs. displacement of proposed RF-MEMS shunt switch using CoventorWare simulation tool 


\section{Conclusion}

We have designed and simulated RF-MEMS capacitive shunt type switch. From the simulated result, characteristics of proposed and designed capacitive shunt switch have been analyzed and studied. Both in UP and DOWN-states, electromagnetic parameters are excellent such as return loss, insertion loss and isolation. Therefore, the proposed switch offers very low losses and has very high isolation property over the frequency range from $0-40 \mathrm{GHz}$. Similarly the proposed switch has also low actuation voltage i.e. 3 Volt due to reduction in length and it minimizes the stickiness between bridge electrode. Therefore, the proposed RF-MEMS switch is very suitable for satellite, radar and microwave applications where high isolation and low losses are required over $0-40 \mathrm{GHz}$ frequency range.

\section{References}

[1] Hsu, T.-R., MEMS \&Microsystems Design and Manufacture. 2002: McGraw Hill.

[2] Rebeiz, G.M., RF MEMS Theory, Design, and Technology. 2003: A John Wiley \& Sons Publication.

[3] Anil Kumar Sahu and B K Sarkar, “A Novel Low Actuation Voltage RF MEMS Shunt Capacitive Switch", 978-1-4244-4819, IEEE 2009.

[4] Preeti Sharma, Shiban K Koul* \& Sudhir Chandra, "Studies on RF MEMS shunt switch", Indian Journal of Pure \& Applied Physics, Vol. 45, April 2007, pp. 387-394

[5] Balachandran, S., et al. "High power nanocrystalline diamond RF MEMS- A combined look at mechanical and microwave. properties. in Microwaves, Communications, Antennas and Electronic Systems", 2008. COMCAS 2008. IEEE International. Conference on. 2008.

[6] Howe, R.T., Surface Micromachining of rmicrosensors and microactuators Journal of Vac. Sci. Technology, Dec 1988. 6: p. 18091813.

[7] Helvajian, H., Microengineering Aerospace Systems. 1999: AIAA.

[8] Feynman, R.P., "There's Plenty ofRoom at the Bottom". Presented at the American Physical Society Meeting in Pasadena CA, Dec 26, 1959.

[9] Ritu Sharma and Dharti Raj Shah, "Design and Analysis of MEMS Capacitive Shunt Type Switch for RF Application", in International Journal of Engineering Sciences \& Research Technology (IJESRT), 179-184, Volume 5, Issue 11, November 2016, ISSN: 2277-9655

[10] Yasser Mafinejad, Abbas Z. Kouzani, Khalil Mafinezhad, Akif Kaynak, "Low Actuation Wideband RF MEMS shunt Capacitive Switch", 2012 International Workshop on Information and Electronics Engineering (IWIEE), SciVerse ScienceDirect, Elsevier, Procedia Engineering 29, 1292-1297, 2012

[11] Ruan, J., et al. ESD stress in RF-MEMS capacitive switches: The influence of dielectric material deposition method in Reliability Physics Symposium, 2009 IEEE International. 2009.

[12] Karl M. Strohm, Bernd Schauwecker, Dietmar Pilz, Winfried Simon, Johann-Friedrich Luy, "RF-MEMS Switching Concepts for High Power Applications", in DaimlerChrysler Research Center Ulm, Wilhelm Runge Straße 11, 89081 Ulm, Germany.

[13] Seong-Dae, L., et al., A novel pull-up type RF MEMS switch with low actuation voltage. Microwave and Wireless.Components Letters, IEEE, 2005. 15(12): p. 856-858.

[14] Malmqvist, R., et al. Design, packaging and reliability aspects of RF MEMS circuits fabricated using a GaAs MMIC foundry. process technology. in Microwave Conference (EuMC), 2010 European. 2010.

[15] Park, J.H., et al., A fully wafer-level packaged RF MEMS switch with low actuation voltage using a piezoelectric actuator. Journal of Micromechanics and Microengineering, 2006. 16: p. 2281.

[16] Lee, H.C., J.Y. Park, and J.U. Bu, Piezoelectrically actuated RF MEMS DC contact switches with low voltage operation. Microwave and Wireless Components Letters, IEEE, 2005. 15(4): p. 202-204.

[17] Kang, S., et al., See-saw type RF MEMS switch with narrow gap vertical comb. J. Semiconductor. Technol. Science, 2007. 7: p. 177-82.

[18] S. P. Pacheco, L. P. B. Katehi and C.-T. Nguyen, "Design of Low Actuation Voltage RF MEMS Switch", 2000 IEEE MTT-S Digest, pp. 165-168.

[19] D. Hah, E. Yoon, and S. Hong, "A Low Voltage Actuated Micromachined Microwave Switch using Torsion Springs and Leverage", 2000 IEEE MTT-S Digest, pp. 157-160.

[20] Goldsmith, C., et al. High-cycle life testing of RF MEMS switches. 2007: IEEE.

[21] Ansoft Corporation - HFSS - www.ansoft.com.

\section{BIOGRAPHIES}

DHARTI RAJ received B.E degree in Electronics and Communication engineering from Nepal board and

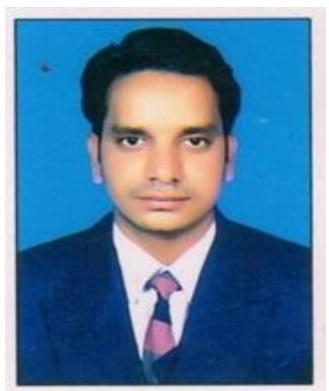
M.Tech degree in RF \& Microwave engineering from Subharti Institute of Technology \& Engineering, SVSU, Meerut, India. His research interests include design and simulation of RF devices for microwave applications, HFSS, MATLAB. He is doing research work on antenna design for UWB applications, frequency reconfigurable antenna using MEMS switch, RF-MEMS capacitive shunt switch design. 
RITU SHARMA received B.Tech degree in Electronics and Communication engineering from UPTU, India

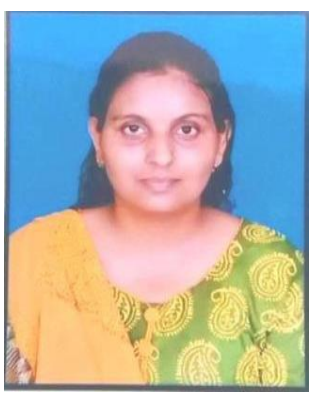
and M.Tech in Electronics and Communication Engineering from Ajay Kumar Garg Engineering College (AKGEC), Ghaziabad, India. She is working as Assistant Professor in the Department of Electronics and Communication Engineering in Subharti Institute of Technology \& Engineering (SITE), Meerut, UP, India. Her areas of interest are antenna design for UWB applications, Plastic Optical Fiber for Advanced Local Area Communication Network (LAN) and RF-MEMS switch design.

HEMANT KUMAR VARSHNEY received B.Tech degree in Electronics and Communication engineering

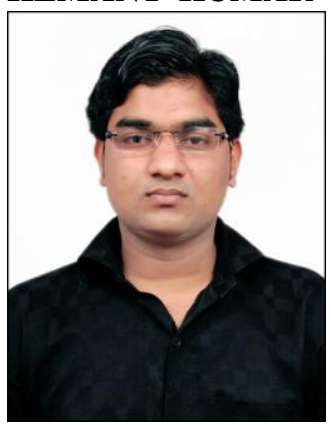
from UPTU Board, India and M.Tech degree in Communication System Engineering from SHIATS, Allahabad, India. Presently he is working as an Assistant Professor in the department of Electronics and Communication Engineering in Dr. B R A College of Agriculture Engg. \& Technology, Etawah, India. His areas of interest are electromagnetics, communication engineering, microstrip antenna design and simulation.

SHAGUFTA PARVEEN ASIF AKHTAR has done Diploma in Industrial Electronics from Maharashtra State

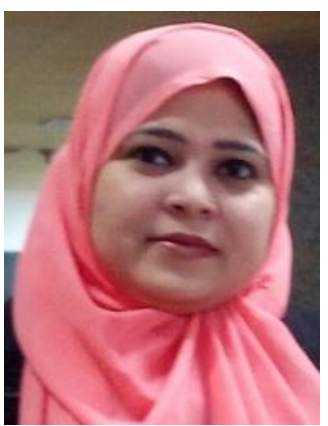
Board of Technical Education and received the B.E degree in Electronics Engineering from Mumbai University and M.Tech in RF \& Microwave Engineering from Swami Vivekanand Subharti University, Meerut, India. Currently she is working as an Assistant Professor in the department of Electronics and Communication Engineering in Vidya College of Engineering, Meerut, India. Her areas of interest are reconfigurable antennas, Fractal antennas, band notching microstrip UWB antennas. 